\title{
LA FILOSOFÍA JURÍDICA Y SU ENSEÑANZA
}

\author{
THE LEGAL PHILOSOPHY AND ITS TEACHING
}

\section{ENZo SOLARI}

Habiendo mencionado cuáles serían, a mi entender, algunas de las condiciones de un curriculum jurídico más razonable que el actualmente existente en $\mathrm{Chile}^{1}$, quisiera ahora, a dicha luz, inquirir en las características que habría de tener la filosofía del derecho en tal curriculum, su modo de enseñanza y el académico encargado de esta. ¿Quién?, ¿cómo? y ¿qué?, en efecto, son las preguntas que plantear cuando se trata de la enseñanza de la filosofía del derecho. Mas, para tratarlas, resulta necesario dar un rodeo. Y es que parece preferible abordar preguntas tan concretas mediante ejemplos, los que son suministrados por quienes, de maneras más o menos eminentes, se han dedicado a la reflexión filosófico-jurídica. Por esto partiré señalando algunos casos de filósofos del derecho, así como de filósofos puros y duros, cuya reflexión ha sido jurídicamente relevante, preguntando no exhaustiva sino solo indicativamente por qué ella ha tenido tal relieve en cada caso. Con alguna respuesta a estas preguntas, y solo entonces, será posible extraer consecuencias curriculares y pedagógicas de tal clase de actividad intelectual.

1. Uno de los mayores iusfilósofos chilenos ha sido Jorge Millas. Su importancia se debe no solo a que haya estudiado universitariamente derecho y filosofía y a que haya estado dotado especialmente para esta última, sino ante todo a que desarrolló una obra filosófica en regla, sobre la base de la cual alcanzó a bosquejar una (bastante sistemática) filosofía jurídica ${ }^{2}$ ¿ ¿Cómo entendía Millas la filosofía del derecho? Se diría que como un ejercicio intelectual, cuya justificación reside en que existen cuestiones vinculadas al derecho que no son -ni pueden ser- abordadas por la dogmática jurídica: en concreto, las de la esencia lógica del derecho, las de su gnoseología, las axiológicas y las propiamente metafísicas. Tales, según Millas, son asuntos filosóficos, no dogmáticos, y lo son porque su tratamiento responsable requiere un saber racional pleno que se esfuerce por ejercitar el pensamiento en los límites de su posibilidad, allende su empleo meramente pragmático. La filosofía simpliciter, decía Millas, es un saber que atañe siempre a la experiencia, pero que a la vez la rebasa y sobrepasa por su propia índole. No se acaba en los nudos contenidos experimentales, sino que además los relaciona e integra. Por eso, cuando la filosofía se aplica prácticamen-

\footnotetext{
* Profesor de la Facultad de Derecho de la Pontificia Universidad Católica de Valparaíso. Avenida Brasil 2950, Valparaíso, Chile. Correo electrónico: enzo.solari@ucv.cl. Licenciado en Ciencias Jurídicas y Magíster en Filosofía de la Pontificia Universidad Católica de Valparaíso y Doctor en Filosofía por la Hochschule für Philosophie/Philosophische Fakultät SJ de München, Alemania. El autor agradece los comentarios y sugerencias de Laura Mayer, y la colaboración de Juanita Olaya para poner a punto el manuscrito.

1 Solari (2012).

2 Por ello, a su muerte, Nicanor PARra pudo decir de él que "era un búho que no podía vivir/ sino en la caverna de las ideas platónicas": PArra (2011) p. 800.
} 
te, como lo hace con el derecho, pretende una integración empírica relativa y orientada a la acción y a la utilidad, pese a que siempre sea un saber que no solo se aquilata por sus virtualidades prácticas o productivas, sino también por su capacidad para satisfacer las perplejidades de la inteligencia ${ }^{3}$. Precisamente en dicha idea de la filosofía se apoya la filosofía jurídica de Millas. En ella se aprecia el dominio de la teoría pura kelseniana y de la filosofía crítica de Kant, aunque también de la teoría de los valores desarrollada en los últimos tres siglos por economistas y filósofos. Esto último tiene su importancia hoy por hoy, cuando se contesta - de distintas maneras- la tesis positivista de la separabilidad conceptual entre derecho y moral. Millas afirmaba por el contrario su conceptual inseparabilidad. El derecho no puede fundar por sí solo su obligatoriedad, su deber ser. Más allá de la validez, de la Grundnorm y de la eficacia, creía Millas, habría que remontarse al fundamento espiritual que está en la base del derecho, y que no es otro que su calidad de bien, de cosa valiosa. El derecho qua derecho obliga porque de su esencia emana un imperativo axiológico. Por ello es menester efectuar una indagación de valores en el campo jurídico; justamente de esta derivan las originales ideas de Millas en torno a la seguridad jurídica y al carácter axiológicamente aberrante que sería connatural a todo sistema jurídico ${ }^{4}$.

2. En Argentina, cuna de grandes filósofos del derecho, se diría que ocurre algo parecido. Las notables contribuciones a la filosofía jurídica que han hecho Carlos Alchourrón y Eugenio Bulygin descansan sobre todo en la formación filosófica de ambos, especialmente en su competencia lógico-semántica. Véase en este sentido, en la introducción a su Normative systems ${ }^{5}$, su sombrío diagnóstico acerca de las consecuencias que habría acarreado el divorcio entre la lógica y el derecho, así como lo que allí proponen -allende los estrechos márgenes de las disciplinas jurídicas- para tratar de manera conceptualmente satisfactoria la noción de sistema jurídico:

"la noción de sistema u orden jurídico como conjunto de todas las normas válidas, cuya validez puede derivarse de alguna fuente común, como el soberano (Austin), la norma básica (Kelsen) o la regla de reconocimiento (Hart), es de relativamente poca utilidad para la ciencia jurídica. Los juristas nunca analizan los problemas de completitud (lagunas) o coherencia (contradicciones) en relación a todo el orden jurídico. Se preguntan a menudo si tal o cual ley o código, o algún conjunto definido de normas, es completo en relación a algún problema específico, pero solo los filósofos del derecho hablan acerca de la completitud de todo el orden. Así, pues, para dar cuenta de la actividad de los abogados y de los juristas se requiere un concepto más general de sistema normativo; la noción de orden jurídico es tan solo un caso especial de aquel. Teniendo en cuenta las dificultades expuestas, se ha elaborado un concepto general de sistema normativo, basado en algunas ideas de Alfred Tarski. El sistema normativo es definido como un conjunto de enunciados que tiene (algunas)

\footnotetext{
3 Millas (2012) pp. 86-162.

4 Millas (2012) pp. 322-404.

5 Alchourrón y Bulygin (1974) pp. 21-22.
} 
consecuencias normativas (para algún universo de casos y algún universo de soluciones). La definición del concepto de sistema en términos de consecuencias normativas permite dar cuenta de enunciados no normativos que pueden figurar en un sistema normativo, sin necesidad de tratarlos como normas incompletas y mutiladas. Al mismo tiempo, el énfasis puesto en las consecuencias permite desentenderse de cuestiones tales como el número o el origen de los enunciados que forman la base del sistema. Cualquier conjunto de enunciados puede usarse como base de un sistema" ${ }^{\text {. }}$

Por lo demás, uno de los inspiradores de estos filósofos del derecho argentinos es Georg Henrik von Wright, quien, con escasos conocimientos jurídicos ${ }^{7}$, pero con sofisticadas herramientas lógicas y conceptuales y con una fina teoría de la acción, ha contribuido grandemente al tratamiento filosófico de problemas jurídicos ${ }^{8}$.

3. Cabría preguntarse: ¿será una peculiaridad latinoamericana -esta de que los mejores iusfilósofos sean filósofos, o bien abogados dotados de una sofisticada y prolongada formación filosófica-? En absoluto. Un ejemplo de otra latitud ha sido Ronald Dworkin. No hay que creer que fuese un abogado practicante que habría logrado cultivar filosóficamente problemas jurídicos; Dworkin era en realidad alguien sumamente competente desde un punto de vista filosófico. Estudió el grado en letras en el College de Harvard y una licenciatura en letras con mención en Jurisprudence en Oxford. Solo después de ello estudió derecho en Harvard y se dedicó a la práctica jurídica en New York. Desde 1962 se desempeñó como profesor de derecho en Yale, Oxford (sucediendo a Hart), New York, etc. Más allá de la biografía académica y jurídica de Dworkin, hay que atender al carácter de su pensamiento, en el cual influyen especialmente H. Hart y J. Rawls, pero también L. Fuller, W. Quine, y con el cual interactúan B. Williams, G. Evans, Th. Nagel, D. Parfit, J. Raz, J. Finnis, G. Cohen, A. Sen'. El mencionado Nagel, filósofo de primera línea, ha reconocido su deuda con Dworkin respecto del afinamiento de argumentos contra el escepticismo, el relativismo y el subjetivismo moral ${ }^{10}$. Dworkin, como se sabe, conocía bien la filosofía del lenguaje y las teorías hermenéuticas. En general, el fundamento intelectual de Dworkin está constituido por "filósofos que escriben insertos en la corriente principal de la filosofía (y quizá de la economía) y no juristas"11. Aún más,

"es un filósofo por naturaleza [...] Va directo al problema, sin una severa búsqueda de lo dicho por otras personas. Tiene una profunda preocupación por el efecto de la filosofía [...] En los escritos de Dworkin no aparecen análisis detallados de lo que otros filósofos han dicho aunque hay una impresionante amplitud de conocimientos

\footnotetext{
6 Alchourrón y Bulygin (1974) p. 23

7 Bulygin (1992) pp. 385-386.

8 Vid. por ej. Von Wright (1979), (1976), (2003a) y (2003b).

9 Para estos datos, me baso en Guest (1993) pp. 576-586.

10 Nagel (2000) pp. 11 y 138 n. 12.

11 Guest (1993) p. 583
} 
de fondo, que abarcan las teorías de la ética, la estética, la economía, el lenguaje y la lógica" 12 .

Dworkin fue un pensador liberal y constitucionalista que parece creer -así lo declaró en El dominio de la vida- que la mejor filosofía jurídica es la que procede desde dentro hacia afuera: "empezar por problemas prácticos, como la cuestión de si la ley debería permitir alguna vez el aborto o la eutanasia, y, si es así, en qué circunstancias, y entonces preguntar qué condiciones generales de naturaleza filosófica o teórica debemos afrontar para resolver esos problemas prácticos"13. Lo que equivale a pensar, como dijera famosamente, que la jurisprudencia o filosofía jurídica "no es sino la parte general de la adjudicación (jurisprudence is no more than the most general part of adjudication)"14.

4. Robert Alexy es otro filósofo del derecho actual que podría pasar ante todo por jurista, en concreto publicista, y uno que solo ha conseguido elevar conceptualmente con cierto éxito sus propias reflexiones jurídicas. Empero, también su caso es el de alguien cuya competencia filosófica le permitiría discutir con filósofos profesionales y ser leído con interés por estos. Alexy estudió derecho y filosofía en Göttingen desde $1968^{15}$. En su doctorado y en su habilitación demuestra no solo un conocimiento especializado de la dogmática jurídica, sobre todo de la constitucional, sino también un agudo conocimiento de la ética analítica, de la teoría crítica en la versión de Habermas, y de las teorías de la argumentación. Según Alexy, y estas declaraciones lo delatan, los mayores filósofos del derecho serían Aristóteles, Hobbes y Kant, y los mayores del siglo XX, Radbruch, Kelsen, Ross y Hart ${ }^{16}$. Cuando habla del panorama actual de la filosofía jurídica en Alemania, Alexy expresa su propia posición respecto al estatuto de la filosofía jurídica:

"con la situación actual de la filosofía del Derecho en Alemania ocurre como con muchas cosas humanas. La situación podría ser mejor, pero uno podría también fácilmente imaginar un estado de cosas peor. Algo bueno es que todas las Facultades ofrecen cursos de filosofía y/o de teoría del Derecho. La calidad ciertamente es muy desigual. Eso tiene diversas causas. Una particularmente importante es que la formación y el interés de los que tienen a su cargo la materia son muy desiguales. En Alemania no hay prácticamente ninguna cátedra dedicada por completo a la filosofía del Derecho o a la teoría del Derecho. Se corresponde con una vieja tradición. No se podría imaginar a un Savigny o a un Ihering sin el Derecho civil, e incluso Kelsen era sin duda un iuspublicista, así como Radbruch un penalista. Esta vinculación con una especialidad dogmática tiene ventajas e inconvenientes. La ventaja consiste sobre todo en que de esa manera se asegura el conocimiento del objeto sobre el que se filo-

\footnotetext{
12 Guest (1993) p. 586

13 DWORKIN (1994) p. 42

14 DWORKin (1986) p. 90.

15 Atienza (2001) p. 5.

16 Atienza (2001) pp. 22-25.
} 
sofa. Todo filósofo del Derecho debe poder dar una respuesta a la pregunta '¿qué es el Derecho?'. Es una trivialidad que aquel que realmente conoce un objeto, en general está en mejores condiciones de decir lo que ese objeto es, en relación con el que no lo conoce o lo conoce solo en forma superficial. En la respuesta a la anterior pregunta llamaba 'filósofos del Derecho en sentido estricto' a los pensadores que eran tanto filósofos como juristas. Ese conocimiento del objeto fundamenta la necesidad de la profesión de filósofo del Derecho en sentido estricto también desde un punto de vista filosófico, pues la pregunta '¿qué es el Derecho?' es, como nadie lo ha expresado mejor que Kant, una pregunta filosófica” ${ }^{17}$.

Tal entreveramiento entre derecho y filosofía, y uno no artificioso sino coherente y necesario, se aprecia constantemente. El mencionado Kant es utilizado profusamente por Alexy, por ej. cuando trata de mostrar en qué consiste un no positivismo superinclusivo (allí Kant es reunido con Tomás de Aquino) y cuando desarrolla transcendentalmente (y a la zaga de Brandom) un argumento explicativo para justificar los derechos humanos. Lo propio hace Alexy con Kierkegaard, que a sus ojos también permite defender la idea de estos derechos con un argumento existencial que apoyaría y complementaría al explicativo ${ }^{18}$.

5. Hans Kelsen (quien, no solo según Alexy sino generalmente, es reconocido como uno de los mayores iusfilósofos del siglo XX) afirma la misma tesis según la cual es preciso tener porte de filósofo profesional para hacer contribuciones a las cuestiones filosófico-jurídicas. En el caso de un kantiano (y neokantiano) como Kelsen la cosa es trivial: ¿qué sería de la Reine Rechtslehre sin la filosofía transcendental - no la crítica de la razón práctica, sino la de la razón pura- de Kant? ${ }^{19}$. Así, por ej., decir que la Grundnorm sea presupuesto lógicotranscendental de la validez de los actos constituyentes -y de los producidos conforme con la constitución - es algo ininteligible sin recurso a la noción kantiana de transcendentalidad:

"en tanto solo mediante la presuposición de la norma fundamental se hace posible interpretar el sentido subjetivo de los actos constituyentes, y de los actos realizados conforme con la constitución, como su sentido objetivo, es decir, interpretarlos como normas jurídicas objetivamente válidas, puede designarse a la norma fundamental, tal como es representada por la ciencia del derecho, y si cabe recurrir per analogiam a un concepto de la teoría kantiana del conocimiento, como la condición lógico-trascendental de esa interpretación. Así como Kant pregunta cómo es posible una interpretación, libre de toda metafísica, de los hechos dados a nuestros sentidos en las leyes naturales formuladas por la ciencia natural, la teoría pura del derecho pregunta: ¿cómo es posible la interpretación, que no eche mano de autoridades metajurídicas, como dios o la naturaleza, del sentido subjetivo de ciertos hechos, como un sistema de normas jurídicas válidas objetivamente, describibles en enunciados

\footnotetext{
17 Atienza, (2001) pp. 26-27, las negritas son mías

18 Alexy (2012) pp. 6 y 10-12.

19 Vid. al respecto Paulson (1991) pp. 173-187.
} 
jurídicos? La respuesta gnoseológica de la teoría pura del derecho es: bajo condición de que se presuponga la norma fundamental 'uno debe comportarse como la constitución lo prescribe', es decir, como corresponde al sentido subjetivo de los actos de voluntad que establecieron la constitución, conforme a las prescripciones del constituyente. La función de esta norma fundamental es fundamentar la validez objetiva de un orden jurídico positivo, es decir, de las normas implantadas mediante actos humanos de voluntad en un orden coactivo eficaz en términos generales; es decir, interpretar el sentido subjetivo de esos actos como su sentido objetivo. La fundamentación de la validez de una norma positiva (esto es: impuesta mediante un acto de voluntad), que obliga a determinada conducta, se efectúa con un procedimiento silogístico. En este silogismo, la premisa mayor es una norma considerada objetivamente válida (o mejor: el enunciado de semejante norma) según la cual debe uno comportarse obedeciendo las órdenes de una determinada persona, es decir, comportarse conforme al sentido subjetivo de esos actos imperativos. La premisa menor afirma el hecho de que esa persona ha ordenado que uno debe actuar de determinada manera; la conclusión afirma la validez de la norma: uno debe comportarse de esa determinada manera. La norma, cuya validez es expresada en la premisa mayor, legitima así el sentido subjetivo del acto imperativo, cuya existencia afirma la premisa menor, como su sentido objetivo [...] La norma que funciona como premisa mayor, en cuanto norma considerada objetivamente válida, es una norma fundamental, si su validez objetiva no continúa siendo cuestionada. No lo es, cuando su validez no puede fundarse en un procedimiento silogístico. Y no puede fundarse así cuando el enunciado del hecho de que esa norma ha sido impuesta por el acto de voluntad de una persona, no es posible como premisa menor de un silogismo [...] Cuando la validez de una norma no puede fundarse de esta manera, tiene que colocársela, como premisa mayor, en la iniciación de un silogismo, sin que ella misma pueda ser afirmada como la conclusión de un silogismo superior que dé fundamento a su validez [...] Si la norma fundamental no puede ser el sentido subjetivo de un acto de voluntad, solo le queda por ser el contenido de un acto intelectual. En otros términos: si la norma fundamental no puede ser una norma querida, siendo sin embargo lógicamente imprescindible su enunciación en la premisa mayor de un silogismo que fundamente la validez objetiva de normas, solo puede ser entonces una norma pensada" 20 .

Aquí se aprecia, dicho sea de paso, aquello contra lo que reaccionan Alchourrón y Bulygin, autores nítidamente kelsenianos, pero que estiman sin embargo que la noción de orden jurídico de Kelsen requiere de correcciones y ampliaciones lógico-semánticas, como vimos.

6. De hecho, el temprano interés de Kelsen por la filosofía ${ }^{21}$ no es raro entre otros de los máximos filósofos del derecho del siglo pasado. Es lo que ocurre con Herbert Hart, cuyos estudios universitarios se desarrollaron en el New College de Oxford en Litterae huma-

\footnotetext{
20 KeLSEN (1982) pp. 209-211, hago alguna corrección a esta traducción.

21 Vid. Walter (2007) p. 1.
} 
niores (= latín, griego, historia antigua y filosofía). Solo después de ellos, Hart se presentó a las Bar examinations para, rechazando la invitación a ser tutor en el New College, dedicarse luego por ocho años a la actividad jurídica profesional como Chancery barrister. Durante la segunda guerra, como se sabe, Hart sirvió a la inteligencia militar británica, manteniendo en la época conversaciones filosóficas con sus vecinos de labor, los filósofos oxonienses Ryle y Hampshire. Acabada la guerra, el New College volvió a invitarlo a ser fellow y tutor de filosofía, y Hart -tras 16 años ausente de Oxford- acepta abandonando la práctica jurídica y pretendiendo "un desafío intelectual más profundo" ${ }^{22}$. Oxford -como Cambridge con Wittgenstein y los suyos- vivía en estado de agitación filosófica: convivían talentosos filósofos como Austin, Ryle, Waisman, Paul (gracias al cual Hart conoció el inédito Cuaderno azul de Wittgenstein), los Warnock, Strawson, Urmson, Woozley, Hare y Foot, un jurista como Honoré - por nombrar a los más notables-. Hasta allí su renovada dedicación a la filosofía no estaba orientada por problemas jurídicos (de hecho, enseñar universitariamente derecho no tenía gran prestigio en Inglaterra, como sí lo tenía dedicarse a la filosofía pura y dura). Sin embargo, a Hart le fue útil la práctica jurídica, pues precisamente a partir del lenguaje jurídico ordinario pudo plantear cuestiones filosóficas con fundamento ${ }^{23}$. De los filósofos del lenguaje ordinario Hart era el único a la vez jurista y filósofo. Puede decirse que en los años 50 Hart se encontró con una filosofía jurídica -la de los decimonónicos Austin y Maine- ya anquilosada ${ }^{24}$. Su obra, en este sentido, consistió en renovar tal filosofía con el sugerente instrumental de Oxford (y Cambridge). En 1952 Hart ocupó una cátedra de filosofía del derecho que había quedado vacante y "emprendió sus tareas mucho más al estilo de un filósofo entre juristas que al de un jurista con intereses filosóficos" 25 . Por eso mismo se han hecho notar los paralelismos entre Ryle, Austin, Wittgenstein y el mismo $\mathrm{Hart}^{26}$. Los cuales no obstan, claro, a que en Hart se perciban también poderosas influencias filosóficas más tradicionales, como la del utilitarismo liberal y la del positivismo jurídico de Hobbes, Hume, Bentham, Austin y Mill27. A Hart le parecía importantísima la filosofía para juristas académicos y prácticos, una formación que agudice las facultades argumentativas para el tratamiento de cuestiones jurídicas ${ }^{28}$. Por ello el año de su muerte, 1992, pudo decir de él otro filósofo del derecho, su discípulo y amigo Joseph Raz:

"por primera vez desde el surgimiento, durante el siglo XIX, de facultades separadas de derecho inglés en Inglaterra, que confiaron la materia a caballeros-juristas encantados de dar rienda suelta a especulaciones de aficionados, una mente filosófica de primera clase se dedicaba a ella. Volviendo a Bentham, Herbert restableció la relación histórica entre la teoría del derecho y las principales tradiciones de la filosofía.

\footnotetext{
22 MacCormick (2010) pp. 61-62; a este autor debo los datos biográficos sobre Hart.

23 MacCormick (2010) pp. 63-64.

24 "La filosofía del derecho en las universidades se había convertido en una rutina de lecturas y relecturas de un canon de textos y manuales": MACCORMICK (2010) p. 89.

25 MacCormick, 2010 , p. 64

26 MacCormick (2010) pp. 82-87.

27 MacCormick (2010) p. 69.

28 De PÁramo (1988) pp. 339-341.
} 
Ofreciendo una jurisprudencia filosóficamente sofisticada, puso los fundamentos para el florecimiento de la materia del que hoy somos testigos"29.

7. Parece claro, pues, que los mejores filósofos del derecho de las últimas décadas han dispuesto de estrictas y rigurosas competencias filosóficas. La conclusión sería la de que es necesario ser filósofo profesional para dedicarse a las cuestiones filosófico-jurídicas -aunque tal cosa no sea suficiente (y es que no todo filósofo, aunque lo pretendiera, ha hecho aportes significativos a la filosofía del derecho)-. Mas, parece también que entre los mejores filósofos del derecho recientes dominaran generalmente los que a la vez han sido juristas y filósofos, vale decir, los que han estudiado derecho, incluso dedicándose a la práctica jurídica, pero poseyendo además una alta competencia específicamente filosófica. He aquí un punto que conviene precisar. Esto, que parece haber ocurrido muchas veces en las últimas décadas, no siempre ha sucedido. De hecho, grandes filósofos han protagonizado el planteamiento de varias de las preguntas filosófico-jurídicas más conspicuas: ¿qué es el derecho?, ¿cómo es posible, y de qué índole es, el conocimiento jurídico?, ¿cuál es la relación entre el derecho y la justicia?, etc.

8. Desde esta perspectiva, la época del idealismo alemán suministra ejemplos del filósofo dedicado a pensar cuestiones jurídicas de manera virtuosa. Si fuera cierto que la filosofía del derecho empieza a autonomizarse como disciplina a partir del siglo XVIII (las expresiones alemanas Philosophie des Rechts y Rechtsphilosophie remontan a 1798, después de lo cual comienzan a popularizarse ${ }^{30}$ ), habría que decir que ya entonces hubo filósofos que, con algunos conocimientos jurídicos pero sin ser formalmente juristas, elaboraron notables filosofías del derecho. Un caso palmario es el de Kant. Su Rechtslehre es parte del sistema de la razón práctica, que esto es la Metaphysik der Sitten, y se deriva -como todas sus partes- de una previa crítica de la razón práctica. La doctrina o metafísica del derecho, dice Kant, presenta a priori un sistema del mismo, sin dejar totalmente de lado algunas observaciones empíricas a propósito de "casos particulares de la experiencia"31. La factura filosófica de esta doctrina del derecho comparece ya desde el inicio de la introducción a la metafísica de las costumbres:

"la facultad de desear es la facultad de ser, por medio de sus representaciones, causa de los objetos de estas representaciones. La facultad de un ser de actuar según sus representaciones se llama vida" 32 .

Idéntica impostación filosófica es notoria en la celebérrima diferencia entre legalidad y moralidad de la acción ${ }^{33}$. O en su característico tratamiento tanto puro como práctico de

\footnotetext{
29 RAZ, (1993) p. 30.

30 Broekman (1992) col. 315.

31 Consigno la paginación según la edición de la Academia a cargo de P. Natorp, pero de hecho uso las sgtes. ediciones: Kant (2001) pp. 205-206, y KanT (2005) pp. 5-6.

32 Kant (2001) p. 211, y (2005) p. 13.

33 Kant (2001) pp. 218-221, y (2005) pp. 23-26.
} 
la libertad ${ }^{34}$. O en su elucidación de lo que es el derecho, del principio universal del mismo y de su vinculación con la coacción ${ }^{35}$. O en la peculiar manera de plantear la distinción de las dos grandes partes de la doctrina del derecho: el derecho privado ${ }^{36}$ y el público ${ }^{37}$. Dentro del derecho privado, notable es la muy material presentación kantiana del derecho conyugal -en el $\$ 24$ de la doctrina general del derecho- como una especie de comunidad sexual (Geschlechtsgemeinschaft, commercium sexuale): si esta "es el uso recíproco que un hombre hace de los órganos y capacidades sexuales de otro (usus membrorum et facultatum sexualium alterius)", entonces el matrimonio (Ehe, matrimonium) es una especial comunidad sexual caracterizable como "la unión de dos personas de distinto sexo con vistas a poseer mutuamente sus capacidades sexuales durante toda su vida", una unión que es por ende natural (porque puede engendrar un semejante), mas no según la mera naturaleza animal sino según la ley (pues el uso y goce que cada cónyuge hace del $-\mathrm{y}$ consigue en ese- otro no es caníbal, es en cambio personal), y en la que la procreación no es su base de legitimación (ya que esta unión es un contrato no arbitrario sino estrictamente necesario, pero que no se disuelve cuando la procreación es imposible o deja de ser posible) ${ }^{38}$. Como es sabido, estas definiciones tan secas y materialistas erigidas por un idealista han levantado comentarios y aun malestares filosóficos en el seno del mismo idealismo alemán ${ }^{39}$. En el derecho público, a su turno, se destaca la defensa kantiana de la pena de muerte ejecutada a la luz de su filosófica defensa de un retribucionismo rigurosísimo en el ámbito penal, dentro del que entra en juego incluso la distinción transcendental entre homo phaenomenon y homo noumenon ${ }^{40}$. En el Anhang a la Doctrina del derecho, Kant agrega algo que suena bastante definitivo: que las cuestiones filosófico-jurídicas han de estar en manos de "filósofos versados en leyes (rechtskundige Philosophen)" que se eleven "hasta los principios metafísicos de la doctrina del derecho (zu den metaphysischen Anfangsgründen der Rechtslehre)" ${ }^{41}$.

9. Hobbes, a su vez, ejemplifica también al filósofo que en cuanto tal ha dejado huella en la teoría política y aun jurídica. Aunque Hobbes estudió latín y griego (tradujo al inglés, como es sabido, la Ilíada, la Odisea y la Historia de la guerra del Peloponeso) y luego lógica y física aristotélica ${ }^{42}$, todo indicaría que estudios tan humanísticos no le impidieron

\footnotetext{
34 Kant (2001) pp. 221-228, y (2005) pp. 26-36.

35 Kant (2001) pp. 229-233, y (2005) pp. 37-43.

36 KANT (2001) pp. 245-308, y (2005) pp. 55-138.

37 Kant (2001) pp. 311-355, y (2005) pp. 139-196.

38 Kant (2001) pp. 277-278, y (2005) pp. 97-98.

39 Solo por ej., vid. las observaciones de Hegel en el Zusatz al $\$ 161$ de las Grundlinien der Philosophie des Rechts y en los \$\$518-519 de la Enziklopädie der philosophischen Wissenschaften im Grundrisse de 1830, en las que defiende que el momento natural del matrimonio está envuelto por una vinculación ética y elevado a determinación espiritual.

40 Kant (2001) pp. 331-337, y (2005) pp. 165-174. Vid. Solari (2008).

41 Kant (2001) p. 357 y (2005) pp. 198-199. Interesante es que Kant, en su ensayo sobre la paz perpetua, afirme muy políticamente: el jurista que no es filósofo tiene la enorme tentación, por su función propia, de aplicar las leyes existentes sin averiguar antes si ellas no requerirían de alguna mejora: KANT (1977) p. 228 (A 66/B 70).

42 Vid. Hobbes (1839) p. xiii.
} 
escribir fructuosamente de derecho y política ${ }^{43}$. De hecho, es ostensible su sesgo filosófico cuando lo hace: para explicar los elementos de las leyes naturales y políticas, dice por ej., hay que conocer lo que sean la naturaleza humana, el cuerpo político y la ley ${ }^{44}$. También su definición de derecho es una conquista al menos parcialmente filosófica: en Elementos derecho es aquello que no es contrario a la razón o, mejor aún, es "la libertad no culpable de usar nuestro poder y habilidad naturales" (HobBes, 2005, p. 172). En el Leviatán Hobbes dice algo no idéntico: que el derecho natural (jus naturale)

"es la libertad que tiene cada hombre de usar su propio poder según le plazca, para la preservación de su propia naturaleza, esto es, de su propia vida; y, consecuentemente, de hacer cualquier cosa que, conforme a su juicio y razón, se conciba como la más apta para alcanzar ese fin” (HobBes, 2000, p. 119).

Por ello, también en el Leviatán, se entrega esta famosa definición de la libertad -lograda al cabo de una prolongada reflexión que lo lleva a separarse de definiciones previas contenidas en los Elementos y en De cive ${ }^{45}-$ :

“el más propio significado de libertad es la ausencia de impedimentos externos, impedimentos que, a menudo, pueden quitarle a un hombre parte de su poder para hacer lo que quisiera, pero que no le impiden usar el poder que le quede, según los dictados de su juicio y de su razón (the proper meaning of LIBERTY is the absence of external obstacles. Such obstacles can often take away part of a man's power to do what he wants, but they can't get in the way of his using his remaining power in obedience to his judgment and reason)" (HoBbes, 2000, p. 119; sobre esto, además, es preciso consultar el cap. 21 del Leviatán).

Esta, por cierto, es la definición característicamente liberal de la libertad, una definición stricto sensu que Hobbes ha obtenido polemizando con la tradición neorromana o republicana de la libertad según la cual solo se es libre cuando no se padece dominación, es decir, cuando no se está sometido a un poder arbitrario, como decía antiguamente Tácito y, siglos después, Milton ${ }^{46}$.

10. Tomás de Aquino, siglos antes, bien enterado de alguna jurisprudencia romana y de fuentes antiguas y medievales, elaboró toda una teoría de la ley, la justicia y el derecho que repercutió en los escolásticos y neoescolásticos posteriores -alcanzando incluso a la actual filosofía política y jurídica-. Esto, dicho sea de paso, sirve para matizar la tesis según la cual el influjo de los teólogos en el derecho ha sido nefasto ${ }^{47}$. No un jurista, en efecto,

\footnotetext{
43 Sobre la formación humanística de Hobbes, vid. SkINNER (2010) pp. 21-31.

44 Hobbes (2005) p. 91.

45 Respecto de las cambiantes comprensiones hobbesianas de la libertad, vid. SKInNER (2010) pp. 33-168.

46 Vid. SKInNER (2010) pp. 169-172.

47 Se ha dicho por ej. que la concepción del derecho como facultad o potestad subjetiva fue teorizada ante todo por teólogos y eclesiásticos. Y que tal concepción reposaría en una miríada de ideas no precisamente jurídicas,
} 
sino un teólogo y filósofo pareciera ser el autor decisivo en las versiones actualmente más sofisticadas de iusnaturalismo ${ }^{48}$. Por otra parte, la teoría jurídica de santo Tomás está esencialmente vinculada con su refinadísima filosofía de la acción humana (actio humana), dentro de la cual la libertad (libero arbitrio) es la que permite distinguirla de la acción que solo puede ser calificada como meramente del ser humano (actio hominis):

"de las acciones que el hombre realiza, solo pueden considerarse propiamente humanas aquellas que son propias del hombre en cuanto que es hombre (propriae hominis inquantum est homo). El hombre se diferencia de las criaturas irracionales en que es dueño de sus actos ([homo] est suorum actuum dominus). Por eso, solo pueden llamarse propiamente humanas aquellas acciones de las que el hombre es dueño. El hombre es dueño de sus actos mediante la razón y la voluntad (per rationem et voluntatem); así, se define el libre albedrío (liberum arbitrium) como facultad de la razón y la voluntad [es cita de Pedro Lombardo, Sent. 2, d. 24, c. 3]. Llamamos, por tanto, acciones propiamente humanas (actiones proprie humanae) a las que proceden de una voluntad deliberada (ex voluntate deliberata procedunt). Si otras acciones convienen al hombre, estas pueden llamarse del hombre (actiones hominis), pero no propiamente humanas, pues no son del hombre en cuanto que es hombre" (STh, I-II, q. 1, a. 1c $)^{49}$.

Tampoco habría que perder de vista que, cuando de las configuraciones institucionales de la libertad y del poder público se trata, Tomás debe ser visto ante todo como filósofo con una genealogía sumamente original: no la un premoderno completamente absorbido por los precedentes de la filosofía griega clásica, sino la de un medieval en cuya teoría política ya se anuncia "la irrupción [...] del ámbito de lo privado y [se] rompe la apoteosis del ámbito de lo público propio del ideal político clásico anunciado por la República de Platón y canonizado por Aristóteles en la Ética y la Política", puesto que su filosofía política, en suma, "no se apoya totalmente ni en el modelo clásico ni en el protomoderno, sino que participa de ambos y se presenta como una suerte de pendant conceptualmente suspendido entre tradición y modernidad" 50 .

sino ambigua y vagamente teológico-filosóficas, cuya promiscua utilización política es moneda corriente en la actualidad: "extrañas ideas de sacerdotes teólogos sobre el derecho [...] Algo excéntricas [...] Es en verdad asombroso cómo una noción ideada por teólogos, no diremos que haya influido, en el acervo técnico del derecho y la política, mas que haya pasado íntegra a él y se haya difundido socialmente con gran fuerza impulsora del pensamiento de los intelectuales, lo mismo que del movimiento de las masas, como incluso lo vemos en el día de hoy, porque no hay agitación social que no venga presentada al amparo de unos derechos que se reclaman como propios": GuZMÁn (2012) pp. 36 y 61. Por cierto, estas afirmaciones ameritarían un detallado tratamiento tanto histórico, como conceptual y político.

48 Lo que es reconocido por todos: vid. Ross (1994) p. 237, en gral. pp. 236-238, RicKEN (1994) pp. 132-153, esp. pp. 142-145, y FinNis (1998) y (2013).

49 Para la versión castellana recurro, aunque alterándola, a TOMÁs DE AQUINO (1997) pp. 37-38. Un buen comentario del pasaje es el de RICKEN (2013) pp. 123-125.

50 Bertelloni, (2010) pp. 39-40. De hecho, Bertelloni prosigue allí una tesis de Arendt y Habermas que en algún sentido emparentaría a Tomás nada menos que con Hobbes: "el De regno posibilitó el tránsito desde la filosofía política clásica, cuyo paradigma es Aristóteles, a la filosofía social moderna, cuyo paradigma es Hobbes” (BERTELLONI, Medieval, p. 25; es cita de Habermas, Jürgen, Theorie und Praxis, Neuwied-Berlin, 1969, tercera edición, p. 18). 
11. Mucho más atrás en el tiempo, la reflexión platónica sobre los principios o criterios éticos fue y ha seguido siendo relevante, puesto que suministra -de la manera más filosófica que sea posible concebir: Platón es casi la filosofía misma- criterios o parámetros para determinar lo que es jurídicamente legítimo. ¿Por qué Sócrates no escapa de la cárcel si podía hacerlo -y sobre todo si pensaba que era inocente de los cargos que se le imputaron y por los que fue condenado-? Su razonamiento está expuesto en el Critón ${ }^{51}$. A la argumentación de Critón, favorable a la popularidad, a la justicia y a las buenas consecuencias de una huida (44b-46a), el Sócrates encarcelado va respondiendo como sigue: (A) "¿Y qué nos importa, querido Critón, lo que la gente crea?” (44c). Yo, dice Sócrates, solo obedezco razones ( $\lambda$ ó $\mathrm{ol}$ ) (46b). Y es que entre las opiniones humanas, a unas hay que reconocerles importancia -son las buenas de los que saben-, mientras que a otras no -las malas de los ignorantes- (46c-47a), y, por ello, hay que dar importancia a "lo que diga el que entiende de cosas justas e injustas" (48a). (B) De allí en adelante prosigue el diálogo mediante razones, sobre la base de la racionalidad dialógicamente obtenida de los siguientes principios: la felicidad el primero, la conexión felicidad-moralidad el segundo, el tercero el reconocimiento de que causar algo malo a otro es una injusticia -aun cuando se la propine a quien haya sido previamente injusto-, y el cuarto el de que violar un acuerdo justo es malo, siempre en el entendido de que escapar de la cárcel y burlar la condena y la ley de Atenas es algo malo, por ello injusto y por ende inmoral y contrario a la felicidad o plenitud humana (48b-53a). (C) Sócrates, entonces, no debe escapar. Más bien debe obedecer la sentencia que lo condena y en general las leyes atenienses, con las cuales toda su vida ha estado de acuerdo ("de hecho aunque no de palabra": 52d). Si no lo hiciera y en cambio pretendiese escapar, haría algo malo violando de paso su concordancia tácita con la ciudad. Cometería un acto injusto y, cometiendo tal injusticia, el derecho de la $\pi$ ó $\lambda ı$ y Atenas misma se vendrían abajo. Es cierto que una sentencia, una ley y un acuerdo pueden ser injustos y que en esa estricta medida cabría legítimamente desobedecerlos. Pero, si todos los ciudadanos violaran las sentencias y las leyes, es claro que la comunidad no podría subsistir. En el fondo, aunque haya injusticias legales, Sócrates tiende a razonar sobre la base de que alguna continuidad hay entre las leyes y la justicia (53a-54e): "la virtud y la justicia son lo más valioso para los seres humanos, así como las costumbres y las leyes” (53c). (D) Al final, Sócrates se muestra efectivamente como alguien que obedece a las leyes y a su propia condena a muerte no por temor, irreflexión o sumisión autoritaria al poder político, sino precisamente porque es alguien que hace lo que hace siempre y solo porque es obediente a argumentos racionales. De ahí que no deje de retar a su interlocutor para que trate de contradecir las razones que ambos han aceptado libremente, cosa que Critón termina reconociendo no ser capaz de llevar a cabo ("realmente, Sócrates, no tengo nada que decir: 'A $\lambda \lambda$ ', $\tilde{\omega} \Sigma \omega ́ \kappa \rho \alpha \tau \varepsilon \varsigma$,

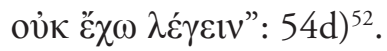

\footnotetext{
51 Sigo, con alguna libertad, PLATÓN (1998).

52 Mayores detalles sobre el Critón como modelo de justificación de una decisión se hallan en Gómez-Lobo (1998) pp. 91-129.
} 
12. ¿Qué prueban exactamente estos casos - desde Kant hasta Platón-? Que incluso un filósofo no jurista puede reflexionar sobre el derecho con pertinencia. Claro que se requiere alguna familiaridad con las leyes y otras normas, con las instituciones y aplicaciones jurídicas, pero pareciera que lo fundamental sería la agudeza filosófica en el tratamiento de aquel material. Si no fuera por esto, ¿cómo entonces podría explicarse el altísimo nivel conceptual y el enorme rendimiento ético y jurídico que alcanzaron las filosofías prácticas de Kant, Hobbes, Tomás y Platón? Claro es, además, que dentro de los sistemas jurídicos modernos la reflexión filosófico-jurídica se ha independizado disciplinariamente de otras reflexiones acerca del derecho. La distinción de ramas dogmáticas y aun saberes jurídicos lo demuestra. Eso implica que el filósofo que piense en el derecho hoy por hoy tendrá que poseer no pocas competencias e informaciones respecto del material jurídico. Excepciones como la de Von Wright tal vez puedan explicarse por el carácter rigurosamente formal que tiene que tener toda investigación lógica. No obstante lo anterior, en los últimos siglos la regla es la de filósofos que son a la vez juristas, gentes entrenadas filosóficamente pero que hablan del derecho con conocimiento de causa, como Millas, Bulygin, Alchourrón, Dworkin, Alexy, Hart y Kelsen. Con todo, se diría que en el derecho, como en otras disciplinas primordialmente técnicas o instrumentales o profesionales, el filósofo podría moverse con soltura y penetración sin satisfacer las mismas exigencias que requieren ciencias estrictas como las matemáticas, la física o la biología. El filósofo de las matemáticas difícilmente podrá no ser un matemático profesional, pero el filósofo del derecho o el cultor de la ética biomédica bien puede no ser abogado o médico. Y es que la ciencia jurídica y la médica no son completamente inaccesibles para el lego, y no lo son porque en realidad no son ciencias, sino técnicas. Ciertamente los saberes instrumentales pueden ser complejos, entre otras razones por su mayor o menor apoyo en ciencias propiamente tales, pero las exigencias intelectivas que plantea una técnica no son comparables a las que supone una actividad puramente teórica. De ahí la mayor posibilidad de suplir la falta de una formación jurídica formal por parte de quienes se acerquen al derecho desde una dedicación tan otra como es la filosófica ${ }^{53}$.

13. ¿Pero no será que lo que vale para eminentes filósofos del derecho no rige del mismo modo para un simple profesor e investigador universitario de filosofía jurídica? Como si en los excepcionales ejemplos examinados el talento filosófico supliera -o en todo caso dominara sobre- la formación jurídica formal, la que en cambio sería requisito principal para elaborar cuestionamientos típicamente filosóficos acerca del derecho. Sin embargo, mi impresión es que aquí habría que razonar a pari, analógicamente. Lo que vale para quienes cultivan la filosofía jurídica creativamente, vale también -salvando las proporciones-

53 La opinión tradicional en contrario, todo hay que decirlo, no ha desaparecido, si bien requiriendo para el jurista volcado en la reflexión teórico-jurídica una intensa y extensa competencia filosófica. Vid. por ej. GUASTINI: "no se puede hacer buena filosofía del Derecho sin ser jurista, sin conocer el Derecho positivo [...] La teoría del Derecho 'sin Derecho positivo' es vacía, pero al mismo tiempo [...] la ciencia del Derecho positivo 'sin teoría' es ciega [...] Quizás merezca la pena subrayar (dado que la cosa podría no ser autoevidente) que la teoría del Derecho puede ser enseñada solo por juristas y solo a estudiantes de Derecho. A pesar de sus evidentes conexiones con la filosofía (en particular con la filosofía analítica), no puede ser enseñada por 'filósofos' desprovistos de conocimientos jurídicos, ni puede ser comprendida por estudiantes que no estudien al mismo tiempo el Derecho positivo": (2004) pp. 457 y 471-472. 
para quienes la cultivan en el plano de la docencia y de una investigación acotada y menos original. Es decir, la competencia filosófica sería indispensable tanto para plantear grandes preguntas y esbozar respuestas o soluciones de envergadura, cuanto para impartir cursos y seminarios que traten dichas preguntas y escribir algunos papers especializados en los que se analicen con detalle ciertos problemas y nuevas vías de tratamiento de aquellas cuestiones fundamentales. Después de todo, lo que muestran superlativamente Platón o Kant, tan interesantemente Kelsen, Hart o Dworkin, y con distinción Millas entre nosotros, es que en una actividad su mayor o menor excelencia está regida por su proximidad o lejanía para con unos casos ideales -esos que Kant llamaba ideales regulativos-. La inalcanzabilidad del ideal no hablaría contra la posibilidad ni contra la necesidad de aquilatar sus realizaciones, y de hacerlo precisamente por su diverso grado de relación particular con aquel ideal. Entonces, si así fuera, también en el caso del docente e investigador universitario promedio se trataría de probar, de gustar (cada cual a su nivel) la experiencia intelectual de aquellos personajes extraordinarios, practicando esa combinación de apertura a la alteridad, rigor analítico y enjuiciamiento normativo en que ha de consistir una filosofía de los variados fenómenos jurídicos -y de señalarla in actu exercito a estudiantes a veces jovencísimos-.

14. Justamente esto permite volver a plantear la pregunta inicial por el lugar y las características que debería poseer la enseñanza de la filosofía del derecho en el curriculum jurídico. Y es que un razonable curriculum - uno aligerado de tanta asignatura dogmática con elefantiásicas cantidades de normas por memorizar- habría de ocuparse no solamente de los componentes cognoscitivo-dogmáticos de la enseñanza (justamente allí donde la educación jurídica chilena se ha hipertrofiado), y además de una dogmática entendida de mala manera (en la medida en que enfatiza hasta el paroxismo la mecánica repetición de normas codificadas, legales y reglamentarias). Sino que también tendría que incorporar altas dosis de los otros componentes indispensables de la enseñanza jurídica: los metodológico-argumentativos (centrados en mejorar las competencias lecto-escritoras y en general las habilidades para el razonamiento) y los críticos, morales y políticos (y que constan no solamente de policies económico-sociales, sino sobre todo del aprendizaje de la justificación razonable de actitudes y juicios valorativos $)^{54}$. La filosofía del derecho, pues, debería jugar un papel capital respecto de todos esos componentes, particularmente del argumentativo y del normativo. ¿Por qué? Porque también universitariamente se trata de que, en el aula y fuera de ella, el profesor permita, facilite que cada estudiante pueda tener y disfrutar, tan sofisticadamente como sea

\footnotetext{
54 Esta tríada de componentes de la enseñanza jurídica, en cuya virtud esta debiese escapar de su (usual tanto en España como en Chile) culto al formalismo, tratando de reunir fructíferamente la teoría con la práctica en el mejor sentido de ambas, la debo a Pérez Lledó (2002) pp. 197-268, esp. pp. 210-261; vid. también, siguiendo casi la misma senda, Flores (2004) y (2005). En idéntica dirección, reuniendo la mejor teoría con la mejor la práctica jurídica, se propone que en asuntos dogmático-jurídicos no puede renunciarse a la inevitable profundización filosófica : “[c]onsidero en detalle el Código Civil alemán; explico cómo su redacción estuvo influenciada por las ideas de Kant, Savigny y Thibaut, Windscheid y Gierke, y argumento que, a no ser que uno entienda estas ideas superiores, no se pueden entender temas centrales en el Derecho Privado alemán actual": GARCíA Jaramillo (2008) p. 42; es cita de EWALD, William, "Comparative Jurisprudence (I) What was it like to try a rat?", en Pennsylvania Law Review, 143, 1994, pp. 1943-1944, citado por. Parejamente habría que proceder cuando se estudia el art. $1^{\circ}$ del Código civil de Chile, o el $4^{\circ}$ de la Constitución chilena, y así por delante.
} 
posible, aquella originaria experiencia pensante que mutatis mutandis han tenido antiguos y modernos, y que aún es posible recrear a partir de una crítica reflexión de los problemas jurídicos actuales. En este sentido el papel de la filosofía en el derecho tendría que ser múltiple. Primeramente, debería estar incrustada en cada disciplina dogmática o directamente profesional no como un acápite aislado (que llevaría, digamos, a tener que contemplar una excéntrica filosofía del derecho laboral, o una del derecho comercial, etc.), sino precisamente como examen radical de sus propios presupuestos y nociones básicas, como pregunta estricta por el razonamiento y las valoraciones que se despliegan en cada una de las ramas jurídicas. Segundo, la filosofía debería generalmente ofrecerse al estudiante de derecho mediante algún curso que posibilite un adecuado entrenamiento en sus herramientas características (conceptuales, lingüísticas, fenomenológicas, metafísicas y normativas): es el régimen de la pregunta, el tratamiento de estructuras complejas, el afinamiento inmisericorde de la crítica, tan necesarios también en una enseñanza eminentemente profesional como la jurídica que puede decirse que son conditio sine qua non de la misma. Y tercero -esto es casi indiscernible de lo anterior-, la filosofía podría encargarse especializadamente (por la vía de cursos obligatorios u optativos) de la tematización de algunas grandes cuestiones jurídicas que escapan del ámbito restringido de cada una de las disciplinas: la cuestión de la moralidad, la de la justicia, la de la argumentación razonable de las cuestiones prácticas, la de la relación del derecho con la sociedad, la literatura y la religión, etc.

15. Solo quisiera, para terminar, precisar mejor estos asuntos a partir de las tres preguntas iniciales: ¿quién debería enseñar filosofía jurídica?, ¿qué tendría específicamente que enseñarse bajo ese rótulo?, y ¿cómo habría de enseñarse tal cosa? Recapitulando, diría por un lado -hablando sensu largissimo- que todo profesor de derecho tiene una tarea de autorreflexión, en el entendido de que debiese incluir explícitamente en su enseñanza unas cuantas reflexiones filosóficas $-\mathrm{y}$ no ornamentalmente, sino respecto de las bases mismas de su propia disciplina- ${ }^{55}$. Pero agregaría, por otro lado, ya más estrictamente, que hay que contar con filósofos propiamente tales que provoquen y desencadenen en sus alumnos la recreación del cuestionamiento específicamente filosófico, docentes suficientemente entrenados en el ejercicio del pensamiento libre y crítico y en el tratamiento sofisticado de sus característicos problemas argumentativos, morales y políticos. Por cierto, esto último supondría contar con profesores capaces de plantear las ideas platónicas, kantianas, etc.,

55 El profesor de derecho procesal civil A. Pérez RAGOne, por ej., sostiene el mismo punto de vista: "durante mis estudios en Tucumán y luego en Brasil, comenzó a gustarme el derecho procesal civil, pero con ingredientes irrenunciables de filosofía política, social y jurídica. De hecho, todo lo que escribo tiene que tener algún elemento de filosofía del derecho y de historia. En mi posgrado en Alemania, además, seguí con mi formación autodidacta, ahora accediendo a los clásicos y modernos en filosofía en general y en filosofía del derecho en particular [...] Decididamente fue en mi formación inicial docente en la Universidad Torcuato Di Tella en Buenos Aires donde terminé convencido de la importancia transversal de una nutrida filosofía del derecho junto a los discípulos de Carlos Nino (especialmente Guido Pincione, Horacio Spector y Roberto Gargarella) [...] Creo que la filosofía del derecho debiera incorporarse e impartirse no solo como una asignatura, sino estar presente transversalmente en la carrera, en formación de habilidades escritas y orales discursivas, en la investigación y la formación metodológica, en el pregrado, en seminarios y en cursos optativos" (comunicación personal al autor: 23.04.2013). 
acerca del derecho, y a la vez conocedores de los sistemas jurídicos contemporáneos en un grado tal que les habilite para plantear preguntas típicamente filosóficas pero de maneras jurídicamente contextualizadas. Entonces, parece deseable que en las escuelas de derecho trabajen filósofos profesionales, los cuales -si bien no imprescindiblemente- podrían ser al mismo tiempo abogados. De hecho, esta afirmación nada tiene de novedosa, si es que

"la calidad de cualquier institución académica depende en definitiva de la profundidad y diversidad de su cuerpo docente, que es el que da forma al plan de estudios de la facultad y es el responsable de los resultados de la enseñanza, del carácter de su biblioteca, y del tipo de estudiantes que son atraídos por la institución. Es el cuerpo docente quien define la facultad" ${ }^{56}$.

Empero, podría pensarse que semejantes juicios son magros, casi triviales. Después de todo, ¿quién discutiría en principio que la filosofía del derecho es justamente filosofía? Mas, quizá no sea tan superflua esta discusión, ni en Chile, donde el curriculum jurídico y las prácticas docentes que de él arrancan fomentan con más frecuencia que la deseable una enseñanza malamente dogmática, escasamente argumentativa y raramente crítica, ni siquiera en países cuya cultura jurídica suele equilibrar más finamente estas diferentes dimensiones pedagógicas e intelectuales, como los EE.UU. Allí, en efecto, se ha propugnado que la enseñanza de la filosofía en general y de la jurídica en particular esté a cargo de filósofos profesionales -en vez de abogados filosóficamente diletantes-. Claro, uno piensa que si se hace tal sugerencia, será porque ella no resulta obvia ni natural, sino que en algún sentido desafía prácticas pedagógicas más o menos consolidadas universitariamente. Pues bien: la sugerencia supone que, en las escuelas americanas de posgrado donde se forman los abogados, quienes se encarguen de impartir cursos especializados en asuntos filosófico-jurídicos sean filósofos profesionales. Dichos filósofos, por supuesto, tendrían que proceder en la docencia tal como Sócrates se conducía en Atenas: tratando, por una aproximación puramente asintótica, de obligar a cada estudiante a realizar continuos autoexámenes de lo que presuntivamente sabe, a admitir reflexivamente y con conocimiento de causa los amplios márgenes de la propia ignorancia, para en fin tratar de obtener dialogadamente buenas razones en el orden de la teoría y, claro, en el de la práctica. Sería deseable, se agrega además, que estos filósofos, permaneciendo con media jornada en el departamento de filosofía (así, sin perder la vinculación con su disciplina originaria), se integren por medio tiempo a una escuela de derecho, donde colaborarían activamente con los docentes más prácticos (abogados y profesionales del derecho) para hacerse competentes en los problemas típicamente jurídicos, de manera tal que puedan plantear rigurosamente las preguntas filosóficas que el derecho suscita. Así, sigue este argumento, el filósofo podría prestar su más específica contribución a los estudiantes y enseñantes del derecho:

"lo que resulta más agravante sobre Sócrates a los atareados profesionales con quienes se topa es el hecho de que él no permitirá arribar a una conclusión nítida.

56 García Jaramillo, 2008, p. 28. Es cita de Fiss, Owen, “El derecho según Yale”, en Böhmer, (1999). 
Siempre hay más indagaciones, siempre más complejidad, siempre más preguntas irritantes" 57 .

De acuerdo con semejantes ideas, claro, parece preferible que filósofos profesionales bien integrados en escuelas derecho (y sin perder el vínculo con sus originales departamentos de filosofía) sean los que impartan asignaturas formalmente filosófico-jurídicas -sin olvidar, conviene repetirlo, la necesidad de que el estudiante de derecho reciba antes de, o durante, sus estudios profesionales de derecho una buena formación humanística y científica, y de que los docentes de dogmática no pasen por alto los componentes filosóficos (especialmente los metodológicos y evaluativos) de sus propias disciplinas-.

16. Qué. Si un previo college a la manera norteamericana (que procure formación en humanidades y algunas ciencias sociales, naturales y matemáticas) fuera deseable pero entre nosotros impracticable, pretendería al menos, dentro de un programa de estudios jurídicos ya sanamente aligerado (y cuando menos semestralizado), una razonable filosoficación -sit venia verbo- de la docencia de ramos dogmáticos. Además, la inclusión de ramos puramente filosóficos y iusfilosóficos, uno o dos quizá con carácter obligatorio, y otros en cambio ofrecidos solo opcionalmente. Interesante en este sentido sería superar el tradicional enfoque histórico de impartir cuestiones filosófico-jurídicas por uno más bien sistemático. Esto permitiría incluir y explorar -iya en el pregrado!- temáticas tales como derecho y sociedad, derecho y religión, o derecho y literatura, según había insinuado, las cuales además posibilitan plantear tanto las mismas cuestiones que actualmente constituyen el status quaestionis de la filosofía jurídica, cuanto aquellos asuntos más ceñidamente chilenos y latinoamericanos que también incumben al iusfilósofo nacional. Lo cual, bien visto, tampoco obsta a la inclusión en dichas asignaturas de una cantidad considerable de lecturas no solamente actuales sino también clásicas ${ }^{58}$. Hart, en este sentido, sugería un curso de lógica y otro de filosofía práctica no solo para un posgrado en derecho, sino para la formación de todo abogado:

57 Nussbaum, 2009, p. 49 y antes pp. 31 y 54-56.

58 Algunas sugerencias a considerar. BRIESKORN da un listado de grandes clásicos iusfilosóficos a tener en cuenta: vid. (1990) pp. 167-169. Moreso ofrece un útil decálogo con obras indispensables de las últimas décadas sobre filosofía moral y política: El lenguaje de la moral de R. Hare, Una teoría de la justicia de J. Rawls, Anarquía, estado y utopía de R. Nozick, Tomando los derechos en serio de R. Dworkin, Ética. Inventando lo bueno y lo malo de J. Mackie, Una teoría de lo bueno y lo correcto de R. Brandt, La ética y los límites de la filosofia de B. Williams, Sobre ética y economía de A. Sen, Fuentes del yo. La construcción de la identidad moderna de Ch. Taylor, y Facticidad y validez. Contribuciones a la teoría del discurso del derecho y del estado democrático de derecho de J. Habermas: vid. (2003), 5 pp. (disponible en http://www.indret.com/pdf/153_es.pdf). Este listado habría de ser complementado con otras obras también de los últimos 50 o 60 años dedicadas a la filosofía jurídica, como la segunda edición de la Reine Rechtslehre de H. Kelsen, El concepto de derecho de H. Hart, la Teoría de la argumentación jurídica de R. Alexy, Ley natural y derechos naturales de J. Finnis, quizá alguna obra de A. Ross, N. Bobbio, J. Raz, N. MacCormick, L. Ferrajoli, C. S. Nino o J. C. Bayón (dejo aparte, aunque convendría incluir también, textos de lógica deóntica y específicamente jurídica, como alguno de J. Jørgensen, G. H. von Wright, U. Klug, E. Betti, G. Kalinowski, A. N. Prior, H.-N. Castañeda, E. Bulygin, C. Alchourrón, J. Hruschka, J. Joerden y otros, y obras de tópica, retórica, argumentación e interpretación, como las de Ch. Perelman, Th. Viehweg, G. Tarello, S. Toulmin, J. Wróblewski, R. Guastini o M. Atienza). En fin, auxilio para conocer mejor la historia de la disciplina iusfilosófica, más bien para el docente que para el estudiante, ofrece Postema (2011) sobre el mundo del common law y más adelante -aún está en preparación- el volumen 12 sobre la tradición del civil law. 
"desearía que se incluyeran en los programas exigidos, tanto para ser profesor como abogado en ejercicio, un curso breve y elemental de lógica simbólica moderna y un curso algo más extenso sobre los problemas básicos de la filosofía moral y política. Para los estudiantes ingleses los temas esenciales de este último curso consistirían en el análisis de problemas concretos acerca de la naturaleza de la autoridad política, tal y como Hobbes, Locke, Hume y Rousseau intentaron responder, así como la evaluación de sus diferentes respuestas" ${ }^{\prime \prime}$.

Pero todo -nuevamente- dentro de una organización curricular que difunda en cada área jurídica el argumento filosófico: un razonamiento de segundo grado sobre los razonamientos jurídicos envueltos en las distintas prácticas o profesiones jurídicas (letrada, judicial, legislativa), la interrogación libre y crítica de las cuestiones más sofisticadamente teóricas que cada disciplina jurídica envuelve ${ }^{60}$, el autoexamen de lo que los prácticos del derecho y las diversas tradiciones tienen por indiscutible o seguro.

17. Y cómo. Tales docentes y contenidos disciplinarios suponen cierta metodología. Obviamente, requieren una planificación detallada de estos cursos, un estilo en el aula donde el socratismo -sin ser excluyente- tenga un lugar destacado, y unas evaluaciones coherentes con aquellos planes y didácticas. El método, no hay que olvidarlo, es el camino para despertar en un alumno el estudio regular, el uso casi obsesivo de bibliotecas, un hábito de lecturas no solo habitual sino diario, el planteamiento ordenado y sistemático de preguntas, la clara formulación de razonamientos complejos, una considerable dedicación a la confección de ensayos, preparación de casos y otras piezas escritas. Por ello, en particular, sería metodológicamente deseable considerar una oferta de cursos específicamente filosóficos de distinto carácter. Alguno al modo de lectio, Lecture o Vorlesung, con públicos más bien masivos. Otro al modo de seminario sobre temas y/o autores destinados a grupos más reducidos. Otro aún a manera de disputatio (incluso quodlibetal), que reúna a dos profesores para enfrentarse y polemizar ante su auditorio alternando la defensa de tesis propias con la crítica de las que el otro formule ${ }^{61}$.

La variedad metódica supone abandonar esa forma degradada y mecánica de la escucha que caracteriza a las malas versiones de la exposición magistral, prefiriendo en cambio una pedagogía que estimule tan complejamente como pueda las distintas habilidades lingüísticas: lectura, audición, escritura y habla. Por lo demás, aquella hegemonía o hinchazón de la escucha (en su peor sentido) podría transformarse (bien entendida) en una escuela

\footnotetext{
59 De PÁramo (1988) p. 341.

${ }^{60}$ Libertad que, dicho sea de paso, tiene su proyección institucional en la libertad de cátedra y de expresión académica (vid. MuÑoz, 2012), en cuya excepcional importancia para la filosofía jurídica no resulta necesario insistir.

${ }^{61}$ Un ejemplo de este último tipo es el Faculty of Law Seminar de posgrado sobre Topics in Political Theory and Philosophy of Law impartido por J. Raz y J. Finnis en la Universidad de Oxford entre febrero y abril de 2003 (debo al profesor C. Orrego noticia de este -en su opinión sensacional- seminario colegiado). La disputatio medieval es una interesante forma de enseñanza y aprendizaje, dicho sea de paso; vid., sobre los géneros literarios de la clásica filosofía medieval, FrIEDMAn (2012) pp. 201-206, y, especialmente sobre quaestio, disputatio y quodlibet, LE Goff (1996) pp. 92-95.
} 
que posibilite el silencio, la lentitud, el titubeo ${ }^{62}$. La misma complejidad metodológica supone también la pretensión de que la filosofía jurídica, si es filosofía, ha de enseñarse (y aprenderse) como un persistente diálogo intelectivo. No se aprende filosofía, solo se aprende a filosofar, y no se aprende a filosofar más que a través del diálogo ${ }^{63}$. Hay que conceder, no obstante, dada la escala masiva de la universidad contemporánea, que esto es difícil de replicar en las aulas, como no sea en los estudios de posgrado, donde quizá haya una oportunidad para cultivar el indispensable vínculo entre maestro y discípulo que caracteriza a la experiencia formativa. Y, sin embargo, cuando se trata filosóficamente del derecho en todo el arco de la vida universitaria, no habría que abandonar del todo este ideal regulativo de educarse con maestros, esos otros intelectualmente más experimentados que uno, en cuyo influjo arrasador (como el de Johnson sobre Boswell y el de Goethe sobre Eckermann) nunca se destacará suficientemente el realismo, el humor, la razonable sofisticación ${ }^{64} \mathrm{y}$, last but not least, cierta intransigencia con las propias pasiones ${ }^{65}$.

\section{BIBLIOGRAFÍA CITADA}

Alchourrón, Carlos y Bulygin, Eugenio (1974): Introducción a la metodología de las ciencias jurídicas y sociales (trad. C. Alchourrón y E. Bulygin, B. Aires, Astrea).

Alexy, Robert (2012): "Law, Morality, and the Existence of Human Rights", Ratio Iuris vol. $25 \mathrm{~N}^{\circ} 1$ : pp. 2-14.

AtienZa, Manuel (2001): "Entrevista a Robert Alexy", Doxa N²4: pp. 5-40.

62 "Poder estar en silencio... Se asegura que, en la actualidad, casi el ochenta por ciento de los adolescentes no llegan a leer un texto en silencio, sin tener como trasfondo el sonido electrónico de la radio, de la televisión, etc. Es terrible, porque el cerebro es incapaz de absorber, de forma simultánea, el ruido y el sentido de algo [...] Paciencia, duda, lentitud. Pascal ya lo dejó dicho: 'si se consigue estar sentado en una silla, en silencio y a solas, en una habitación, es que se ha recibido una buena educación'. Es algo terriblemente difícil": STEINER y LADJALI (2005) pp. 105-106.

63 Vid. Kant (1966) p. 698 (correspondiente a la Logik Dohna-Wundlacken). Respecto de la potencia creadora del diálogo y la actividad filosófica, es difícil exagerar la importancia de Sócrates, Platón y, en general, de Grecia: "la incandescencia de la creatividad intelectual y poética en la Grecia continental, Asia Menor y Sicilia durante los siglos VI y V a. C. sigue siendo única en la historia humana. En algunos aspectos, la vida intelectual posterior es una profusa nota a pie de página a ella [...] Porque, seamos claros, aquello fue un milagro": STEINER (2012) pp. 27-28.

64 "Después, he descubierto con la edad [...] que magis magnos clericos non sunt magis magnos sapientes. Pero todavía tengo dudas acerca de cómo puede suceder que un alma rica por el conocimiento de tantas cosas (une âme riche de la connaissance de tant de choses) no se vuelva más viva y más despierta (n'en devienne pas plus vive, et plus éveillée), y que un espíritu zafio y vulgar (un esprit grossier et vulgaire) pueda albergar en su interior, sin mejora, los razonamientos y juicios de los espíritus más excelentes (les discours et les jugements des plus excellents esprits) que el mundo ha dado (que le monde ait porté)": DE Montaigne (2007) p. 166.

65 "Siempre digo a mis alumnos: 'uno no transige con sus pasiones. Las cosas que voy a tratar de presentarles son las que más me gustan. No veo necesidad de justificarlas' [...] Lo peor de todo es desplegar una dialéctica de la excusa, de la apologética [...] Porque se trata de una apologética que nace de la vergüenza por las propias pasiones. Si un estudiante percibe que uno está un poco loco, poseído de alguna manera por aquello que enseña, es un primer paso. Quizá no esté de acuerdo; quizá se burle; pero escuchará; se trata del milagroso instante en que comienza a establecerse el diálogo con una pasión. Nunca hay que buscar una justificación”: STEINER y LADJALI (2005) pp. 115-116. 
Atienza, Manuel (2004): "Entrevista a Riccardo Guastini” (trad. M. Atienza, Doxa № 27: pp. 457-473).

Bertelloni, Francisco (2010): "La teoría política medieval entre la tradición clásica y la modernidad”, en Roche, Pedro (coord.), El pensamiento político en la edad media (Madrid, F. R. Areces) pp. 17-40.

BRIESKORN, Norbert (1990): Rechtsphilosophie (Stuttgart, Kohlhammer).

Broekman, Jan (1992): "Rechtsphilosophie", en Ritter, Joachim y Gründer, Karlfried (edits.), Historisches Wörterbuch der Philosophie Vol. 8 (Darmstadt, WBG) cols. pp. 315-327.

Bulygin, Eugenio (1992): "Entrevista a Georg Henrik von Wright”, Doxa No 12: pp. 385-392.

De Montaigne, Michel (2007): Los ensayos (según la edición de 1595 de Marie de Gournay) (trad. J. Bayod, Barcelona, Acantilado).

De PÁramo, Juan Ramón (1988): "Entrevista a H. L. Hart”, Doxa N 5: pp. 339-361.

Dworkin, Ronald (1994): El dominio de la vida. Una discusión acerca del aborto, la eutanasia y la libertad individual (trad. R. Caracciolo y V. Ferreres, Barcelona, Ariel).

Dworkin, Ronald (1986): Law's Empire (Cambridge, Harvard University Press,).

FInNIS, John (1998): Aquinas: Moral, Political and Legal Theory (Oxford/New York, Oxford University Press).

Finnis, John (2013) “Aquinas' Moral, Political, and Legal Philosophy”, en Stanford Encyclopedia of Philosophy. Disponible en: <http://plato.stanford.edu/entries/aquinas-moralpolitical/>.

Flores, Imer (2004): "Prometeo (des)encadenado: la enseñanza del derecho y los estudios de posgrado", Derecho y cultura $\mathrm{N}^{\circ}$ 14-15: pp. 93-127.

Flores, Imer (2005): "Protágoras vis-a-vis Sócrates: los métodos de enseñanza-aprendizaje del derecho", en Serna de la Garza, J. M. (coord.), Metodología de derecho comparado. Memoria del Congreso Internacional de Culturas y Sistemas Jurídicos comparados (México, UNAM) pp. 125-151.

Friedman, Russell (2012): “Latin philosophy, 1200-1350”, en Marenbon, John (edit.), The Oxford Handbook of Medieval Philosophy (Oxford, OUP) pp. 192-244.

García Jaramillo, Leonardo (2008): "Un nudo gordiano en la enseñanza del derecho. A propósito de la integración de la filosofía jurídica en la dogmática y en la práctica jurídicas", Academia. Revista sobre enseñanza del derecho, Año $6 \mathrm{~N}^{\circ}$ 12: pp. 23-62.

Gómez-Lobo, Alfonso (1998): La ética de Sócrates (trad. A. Palet, Stgo. de Chile, Andrés Bello).

Guest, Stephen (1993): "Ronald Dworkin" (trad. M. Rojas y M. Manson), Revista de ciencias sociales. Universidad de Valparaíso Vol. 38: Ronald Dworkin. Estudios en su homenaje: pp. 573-601.

GuZMÁn, Alejandro (2012): "La introducción del concepto de derecho-facultad ('derecho subjetivo') en la ciencia jurídica y en la política”, Legal Roots. The International Journal of Roman Law, Legal History and Comparative Law $\mathrm{N}^{\circ}$ 1: pp. 23-61.

HobBes, Thomas (1839): Vita, en Opera philosophica quae latine scripsit omnia in unum corpus nunc primum collecta Vol. 1 (Londres, Johannes Bohn).

HobBes, Thomas (2005): Elementos de derecho natural y politico (trad. D. Negro, Madrid, Alianza).

HobBes, Thomas (2000): Leviatán (trad. C. Mellizo, Madrid, Alianza). 
Kant, Immanuel (2001): Die Metaphysik der Sitten (Stuttgart, Reclam).

Kant, Immanuel (2005): La Metafísica de las Costumbres (trad. A. Cortina y J. Conill, Madrid, Tecnos).

Kant, Immanuel (1977): “Zum ewigen Frieden”, en Schriften zur Antropologie. Geschichtsphilosophie, Politik und Pädagogik Vol. 1 (Frankfurt a. M., Suhrkamp) pp. 191-251.

KanT, Immanuel (1966): Gesammelte Schriften IV/1, Vol. 24/2: Vorlesungen über Logik (Berlín, Walter de Gruyter).

Kelsen, Hans (1982): Teoría pura del derecho (trad. R. Vernengo, México, UNAM, segunda edición).

Le Goff, Jacques (1996): Los intelectuales en la edad media (trad. A. Bixio, Barcelona, Gedisa).

MacCormick, Neil (2010): H. L. A. Hart (trad. J. Pérez, M. Pons, Madrid/Barcelona/B. Aires, segunda edición).

Millas, Jorge (2012): Filosofía del derecho (Santiago. de Chile, Ediciones Universidad Diego Portales).

Moreso, José Juan (2003): “Diez libros de filosofía moral y política (1950-2000)”, InDret, Working Paper $\mathrm{N}^{\circ}$ 153: 5 pp. Disponible en: <http://www.indret.com/pdf/153_es.pdf>.

MuÑoz, Fernando (2012): "La necesidad de regular la docencia universitaria en Chile: una propuesta de lege ferenda”, Revista Chilena de Derecho Vol. 39 № 3: pp. 891-907.

Nagel, Thomas (2000): La última palabra. La razón ante el relativismo y el subjetivismo (trad. P. Bargallo y M. Alegre, Barcelona, Gedisa).

Nussbaum, Martha (2009): "El uso y abuso de la filosofía en la enseñanza del derecho", Academia. Revista sobre enseñanza del derecho, Año $7 \mathrm{~N}^{\circ}$ 14: pp. 31-57.

PARrA, Nicanor (2011): Obras completas \& algo + (1975-2006) (Barcelona, Galaxia Gutenberg).

Paulson, Stanley (1991): "La alternativa kantiana de Kelsen: una crítica" (trad. J. García Añón), Doxa N 9: pp. 173-187.

Pérez Lledó, Juan (2002): “Teoría y práctica de la enseñanza del derecho”, Anuario de la Facultad de Derecho de la Universidad Autónoma de Madrid No 6: pp. 197-268.

Platón (1998): Critón (trad., análisis y notas A. Gómez-Lobo, Stgo. de Chile, Universitaria).

Postema, Gerald (2011): A Treatise of Legal Philosophy and General Jurisprudence Volumen

11: Legal Philosophy in the Twentieth Century: the Common Law World (Dordrecht/Heidelberg/Londres/N. York, Springer).

Raz, Joseph (1993): "En memoria de H. L. A. Hart” (trad. J. Ruiz Manero), Doxa N 13: pp. 27-30.

Ricken, Friedo (1994): "Naturrecht I", en Krause, G. y Müller, J. G. (edits.), Theologische Realenziklopädie Vol. 24 (Berlín, Walter de Gruyter) pp. 132-153.

Ricken, Friedo (2013): Allgemeine Ethik (Stuttgart, Kohlhammer, quinta edición).

Ross, Alf (1994): Sobre el derecho y la justicia (trad. G. Carrió, B. Aires, Eudeba).

SkInNER, Quentin (2010): Hobbes y la libertad republicana (trad. J. Udi, Bernal, Universidad Nacional de Quilmes Editorial).

Solari, Enzo (2008): "La pena de muerte según Kant", en Rodríguez, Luis (coord.), Delito, pena y proceso. Libro homenaje a la memoria del profesor Tito Solari Peralta (Santiago. de Chile, Editorial Jurídica de Chile) pp. 21-40. 
Solari, Enzo (2012): "El currículo chileno de estudios jurídicos", Revista de Derecho. Pontificia Universidad Católica de Valparaíso No 39: pp. 703-734.

Steiner, George y Ladjali, Cécile (2005): Elogio de la transmisión. Maestro y alumno (trad. G. Cantera, Madrid, Siruela).

Steiner, George (2012): La poesía del pensamiento. Del helenismo a Celan (trad. M. CónDOR, Madrid, Siruela).

Tomás de Aquino (1997): Suma de teología Vol. 2 (trad. A. Martínez et al., Madrid, Biblioteca de Autores Cristianos).

VON Wright, Georg Henrik (1979): Norma y acción. Una investigación lógica (trad. P. García, Madrid, Tecnos).

VON Wright, Georg Henrik (1976): "Reencuentro con la lógica deóntica”, en VV.AA., Derecho, filosofia y lenguaje. Homenaje a Ambrosio Gioja (trad. E. Bulygin, Astrea, B. Aires), pp. 225-235.

Von Wright, Georg Henrik (2003a): “¿Hay una lógica de las normas?” (trad. D. GonZÁLEZ), Doxa No 26: pp. 31-52.

VON Wright, Georg Henrik (2003b): "Valor, norma y acción en mis escritos filosóficos. Con un epílogo cartesiano" (trad. L. Manrique y P. Navarro) Doxa N 26: pp. 53-78.

WaLter, Robert (2007): "Kelsen. Leben und Werk", Rechtstheorie Vol. 38 N 1: pp. 1-8. 